\title{
ANALISIS KANDUNGAN MERKURI (Hg) PADA LIMBAH HASIL PENGOLAHAN EMAS DI GUNUNG NONA DESA WAPSALIT PULAU BURU
}

\author{
L. S. Sello ${ }^{1}$, A. Mariwiy ${ }^{\star}{ }^{\star}$ Nazudin $^{1}$ \\ ${ }^{1}$ Departement of Chemistry-FKIP, Pattimura University Ambon \\ *abrahammariwy@gmail.com
}

\begin{abstract}
The research had been done to analyze the mercury $(\mathrm{Hg})$ content in waste from gold processing (tailing) at Nona Mountain Wapsalit Village Buru Island. The dry sample was prepared by putting it into the oven at $40^{\circ} \mathrm{C}$ temperatures in two days and then the wet destruction was performed with $10 \mathrm{~mL}$ concentrated $\mathrm{HNO}: \mathrm{HCl}$ ratio (1: 1) while stirring. The tailing was analyzed by using CV-AAS to know about the mercury $(\mathrm{Hg})$ content. The result showed that average mercury $(\mathrm{Hg})$ content at the location I was $721,43 \mathrm{ppm}$ and at the location II was $344,88 \mathrm{ppm}$. Thus, the results showed that tailing concentration at the location I had average mercury $(\mathrm{Hg})$ content higher than at the location II.
\end{abstract}

Keywords: Mercury (Hg), Tailing, Nona Mountain Wapsalit Village.

\begin{abstract}
ABSTRAK
Telah dilakukan penelitian untuk menganalisis kandungan merkuri $(\mathrm{Hg})$ pada limbah hasil pengolahan emas (tailing) di Gunung Nona Desa Wapsalit Pulau Buru. Sampel tailing kering dipreparasi dengan cara dimasukkan di dalam oven pada suhu $40^{\circ} \mathrm{C}$ selama 2 hari, kemudian dilakukan dekstruksi basah dengan perbandingan $\mathrm{HNO}_{3}: \mathrm{HCl}$ pekat (1:1) sebanyak $10 \mathrm{~mL}$ sambil diaduk. Sampel tailing dianalisis menggunakan SSA - Uap Dingin untuk mengetahui kandungan merkuri $(\mathrm{Hg})$. Hasil analisisi menunjukkan bahwa rata-rata kandungan merkuri $(\mathrm{Hg})$ pada titik lokasi I sebesar $721,43 \mathrm{ppm}$ dan titik lokasi II sebesar 344,88 ppm. Hasil ini menunjukkan bahwa tailing pada titik lokasi I memiliki rata-rata kandungan merkuri $(\mathrm{Hg})$ lebih tinggi konsentrasinya dibandingkan konsentrasi pada lokasi titik II.
\end{abstract}

Kata Kunci: Merkuri (Hg), Tailing, Gunung Nona Desa Wapsalit.

\section{PENDAHULUAN}

Limbah hasil pengolahan emas (tailing) adalah jenis limbah yang termasuk dalam Bahan Berbahaya dan Beracun (B3) yang berpotensi dapat merusak lingkungan hidup. Limbah ini banyak dihasilkan dari kegiatan penambangan emas tradisional yang masih dilakukan menggunakan teknik sederhana dan murah. Dalam proses penambangan emas, merkuri digunakan sebagai bahan pemisah antara emas dengan bijihnya yang terdapat pada bantuan yang biasanya disebut dengan proses amalgamasi (Widiowati, 2008). Pada proses tersebut, pemisahan antara emas dengan bijihnya dilakukan dengan cara mencampur batuan yang mengandung logam emas dengan merkuri menggunakan tromol (Sualang, 2001 dalam Kitong dkk, 2012). Proses pengolahan emas menggunakan metode amalgamasi banyak di pakai oleh para penambang emas di Indonesia, salah satunya di daerah Gunung Nona Pulau Buru.

Gunung Nona merupakan salah satu Gunung di Pulau Buru yang memiliki kandungan emas yang cukup melimpah. Gunung ini berada di Desa Wapsalit Kecamatan Lolongguba Kabupaten Buru Provinsi Maluku dan secara geografis, terdapat di hulu Sungai Wai Pamali. Pada daerah ini, terdapat kegiatan penambangan emas secara ilegal yang dimulai dari Tahun 2014 dimana para penambang memanfaatkan merkuri untuk proses pengolahan emas secara amalgamasi untuk mengikat emas. Limbah dari pengolahan tersebut kemudian dibuang ke Sungai Wai Pamali, dimana air dari sungai tersebut mengalir ke Waduk Pamali yang sehari-hari dimanfaatkan oleh 
masyarakat Desa Grandeng untuk irigasi sawah. Lingkungan yang terkontaminasi oleh merkuri dapat membahayakan kehidupan manusia karena merkuri dapat terakumlasi melalui rantai makanan. Merkuri terakumulasi dalam mikroorganisme yang hidup di air (sungai, danau, laut) melalui proses metabolisme. Bahan-bahan yang mengandung merkuri yang terbuang kedalam sungai atau laut dimakan oleh mikroorganisme tersebut dan secara kimiawi berubah menjadi senyawa metil-merkuri (Mirdat dkk, 2013). Berdasarkan hasil penelitian yang dilakukan oleh Male dkk, (2013) dengan menggunakan metode dekstruksi basah dan instumen ICP-MS, jumlah merkuri yang terdapat pada kolam penampungan limbah tromol di Gunung Botak Pulau Buru lebih dari 680 $\mathrm{mg} / \mathrm{Kg}$. Sedangkan konsentrasi merkuri pada sedimen yang terdapat di pesisir Teluk Kayeli yang menjadi muara Sungai Wai Pamali konsentrasinya lebih dari 7,66 mg/Kg. Hasil penelitian Mariwy dkk, (2019) juga menunjukkan bahwa muara dari 4 sungai utama yang bermuara di Teluk Kayeli yaitu Sungai Suket, Wailata, Anahoni dan Waiapu telah tercemar merkuri.

Limbah tailing hasil pengolahan emas yang mengandung merkuri sangat berbahaya jika langsung dibuang ke lingkungan sebab dapat membahayakan kesehatan masyarakat dan ekosistem yang berada di daerah sekitar tempat pengolahan emas tersebut. Oleh karena itu, penelitian ini dilakukan dengan tujuan untuk mengetahui kandungan merkuri pada tailing hasil pengolahan emas di Gunung Nona Desa Wapsalit Pulau Buru.

\section{METODE PENELITIAN}

Penelitian ini dilaksanakan pada Laboratorium Kimia Anorganik FMIPA Unpatti Ambon meliputi penyiapan sampel, dekstruksi sampel dan identifikasi merkuri pada sampel, pengukurannya dilakukan pada Laboratorium Baristand Manado.

\section{Pengambilan Sampel Tailing}

Sampel Tailing dalam penelitian ini diambil dari lahan tempat beroperasinya pengolahan bijih emas pada daerah Gunung Nona dengan jarak tiap titik sampel adalah $\pm 100 \mathrm{~m}$. Koordinat setiap titik sampel tersebut ditentukan menggunakan GPS. Setelah itu diukur parameter fisika dan kimia dari sampel berupa pengukuran $\mathrm{pH}$ dan suhu. Sampel kemudian diambil menggunakan sekop kecil dan dimasukan dalam plastik sampel kemudian disimpan dalam cool box yang telah berisi es batu untuk analisis kandungan merkuri $(\mathrm{Hg})$ di laboratorium.

\section{Pengukuran Kandungan Merkuri Pada Sampel Tailing}

Sampel Tailing awalnya dipisahkan dari pengotor berupa batu, pasir dan kayu selanjutnya dikeringkan dalam oven pada suhu $40^{\circ} \mathrm{C}$ selama 2 hari. Sampel yang telah kering kemudian digerus dengan menggunakan mortal dan alu. Serbuk tailing yang telah halus selanjutnya ditimbang dan ditambahkan pelarut $\mathrm{HNO}_{3}: \mathrm{HCl}$ pekat (1:1) sebanyak $10 \mathrm{~mL}$ sambil diaduk. Setelah itu, larutan dipanaskan di atas hotplate pada suhu $100^{\circ} \mathrm{C}$ selama satu jam dan ditambahkan $5 \mathrm{~mL}$ $\mathrm{H}_{2} \mathrm{O}_{2} 30 \%$ sedikit demi sedikit sampai larutannya tidak berwarna. Larutan kemudian didinginkan dan disaring dengan menggunakan kertas saring Whatman 42 untuk selanjutnya diukur kandungan logam $\mathrm{Hg}$ pada panjang gelombang 253,7 nm dengan menggunakan SSA Uap - dingin.

\section{HASIL PENELITIAN}

\section{A. Penentuan Titik Lokasi Pengambilan Sampel}

Pengambilan sampel dilakukan pada 21 Januari 2018 pada pukul 12:29 WIT.Keadaan cuaca pada saat pengambilan sampel cerah berawan. Tailing diambil dari tempat pengolahan emas di Gunung Nona Desa Wapsalit, Kecamatan Lolongguba, Kabupaten Buru. Penentuan titik lokasi pengambilan sampel dilakukan menggunakan GPS. Lokasi pengambilan sampel berada pada titik koordinat $3,51^{\circ}$ LS dan 126,79 BT. Pada setiap titik diambil 2 sampel dengan tujuan untuk mengetahui perbandingan konsentrasi dan dianggap mewakili daerah sampling. Titik pengambilan 
sampel ditentukan dengan tujuan untuk melihat sebaran pencemaran logam merkuri berdasarkan besarnya konsentrasi. Sebelum proses pengambilan sampel, dilakukan uji parameter fisika dan kimia terhadap $\mathrm{pH}$ dan suhu. Pengujian $\mathrm{pH}$ dan suhu sangat penting dilakukan pada penelitian ini, dikarenakan adanya hubungan erat antara kandungan logam merkuri pada tailing dengan perubahan suhu dan $\mathrm{pH}$ seperti yang terlihat pada Tabel 1.

Tabel 1. Parameter Fisika dan Kimia terhadap pH dan Suhu Pada Tiap Sampel

\begin{tabular}{|c|c|c|c|}
\hline Kode Sampel & Koordinat GPS & $\mathrm{pH}$ & Suhu $\left({ }^{\circ} \mathrm{C}\right)$ \\
\hline Titik I Sampel 1 & $3,51^{\circ}$ LS $126,79^{\circ} \mathrm{BT}$ & 9,5 & 25 \\
\hline Titik I Sampel 2 & $3,51^{\circ}$ LS $126,79^{\circ} \mathrm{BT}$ & 9,4 & 26 \\
\hline Titik II Sampel 1 & $3,51^{\circ}$ LS $126,79^{\circ} \mathrm{BT}$ & 7,7 & 25 \\
\hline Titik II Sampel 2 & $3,51^{\circ}$ LS $126,79^{\circ}$ BT & 7,4 & 27 \\
\hline
\end{tabular}

Berdasarkan baku mutu standar dari KepMen LH No.51 Tahun 2004 pH sedimen berkisar antara $6,5-8,5$. Berdasarkan data yang diperoleh dapat dilihat bahwa $\mathrm{pH}$ pada titik I sampel 1 dan 2 melebihi ambang batas baku mutu $\mathrm{pH}$ pada sedimen, sedangkan sampel pada titik II sampel 1 dan 2 sesuai dengan baku mutu $\mathrm{pH}$ sedimen. Hasil pengujian $\mathrm{pH}$ menunjukkan bahwa sedimen pada titik I sampel 1 dan 2 tergolong basa. Hal ini dikarenakan dalam proses pengolahan emas dilakukan penambahan semen untuk mengikat zat pengotor selain emas. Kalsium, silikat dan aluminat dalam semen beraksi dengan air sehingga menghasilkan kalsium hidroksida $\mathrm{Ca}(\mathrm{OH})_{2}$ yang merupakan basa kuat (Putra,2009). Persamaan reaksi pembentkan $\mathrm{Ca}(\mathrm{OH})_{2}$ dapat dilihat pada persamaan reaksi berikut:

$$
\mathrm{CaO}_{(\mathrm{aq})}+\mathrm{H}_{2} \mathrm{O}_{(\mathrm{aq})} \rightarrow \mathrm{Ca}(\mathrm{OH})_{2(\mathrm{aq})}
$$

Berdasarkan baku mutu standar dari KepMen LH No.51 Tahun 2004 suhu sedimen berkisar $28-32^{\circ} \mathrm{C}$. pengukuran yang dilakukan pada titik I sampel 1 memiliki suhu $25^{\circ} \mathrm{C}$ dan sampel 2 memiliki suhu $26^{\circ} \mathrm{C}$ serta pada titik II sampel 1 memiliki suhu $25^{\circ} \mathrm{C}$ dan sampel 2 memiliki suhu $27^{\circ} \mathrm{C}$. Suhu pada sedimen yang semakin tinggi akan meningkatkan pembentukan ion logam berat merkuri, sehingga mengakibatkan peningkatan proses pengendapan yang berakibat pada tingginya penyerapan logam berat oleh sedimen. Dengan demikian peningkatan suhu juga meningkatkan konsentrasi merkuri pada sedimen (Hatugalung, 2004).

\section{B. Pengukuran Merkuri (Hg) dalam Sampel Tailing}

Proses pengukuran kandungan merkuri (Hg) pada sampel tailing dititik lokasi I dan II, diawali dengan proses pemisahan sampel dari zat-zat pengotor seperti batu, pasir, kayu yang dapat mempengaruhi proses ekstraksi sampel. Selanjutnya sampel tailing yang sudah diketahui berat awal, dikeringkan dalam oven pada suhu $40^{\circ} \mathrm{C}$ selama 2 hari. Menurut Malle, (2013) dalam penelitiannya sampel sebelum dilakukan destruksi dikeringkan dalam oven selama 2 hari pada suhu $40^{\circ} \mathrm{C}$ agar menurunkan kandungan air pada sampel. Merkuri jika tidak bersenyawa dengan unsur lain akan mengalami penguapan pada suhu ruang diatas $25^{\circ} \mathrm{C}$. Akan tetapi, jika bersenyawa dan terikat dengan unsur lain maka memerlukan suhu yang lebih tinggi.

Sampel tailing selanjutnya didestruksi menggunakan larutan $\mathrm{HNO}_{3}: \mathrm{HCl}(1: 1)$. Penggunaan larutan asam klorida dan asam nitrat bertujuan untuk meningkatkan efisiensi ekstraksi logam berat merkuri dalam sampel tanah dan akar padi (Susila, 2012). Reaksi antara asam nitrat dengan asam klorida adalah sebagai berikut :

$$
3 \mathrm{HCl}_{(\mathrm{aq})}+\mathrm{HNO}_{3(\mathrm{aq})} \rightarrow \mathrm{Cl}_{2(\mathrm{~g})}+\mathrm{NOCl}_{(\mathrm{g})}+2 \mathrm{H}_{2} \mathrm{O}_{(\mathrm{l})}
$$

Setelah itu, larutan dipanaskan pada suhu $100{ }^{\circ} \mathrm{C}$ selama satu jam dengan tujuan mempercepat reaksi yang terjadi antara sampel tailing dengan larutan asam dan ditambahkan $5 \mathrm{~mL}$ $\mathrm{H}_{2} \mathrm{O}_{2} 30 \%$ hingga warna pada larutan menghilang. Penggunaan $\mathrm{H}_{2} \mathrm{O}_{2}$ dapat meningkatkan kemampuan oksidasi serta meningkatkan kinerja disolusi dari asam nitrat (Anderson, 1991). Reaksi yang terjadi yaitu sebagai berikut : 


$$
\mathrm{Hg}^{2+}{ }_{(\mathrm{aq})}+\mathrm{Cl}_{(\mathrm{g})}+\mathrm{NOCl}_{(\mathrm{g})}+2 \mathrm{H}_{2} \mathrm{O}_{(\mathrm{l})} \rightarrow \mathrm{Hg}^{2+}{ }_{(\mathrm{g})}+2 \mathrm{H}_{2} \mathrm{O}_{(\mathrm{l})}+4 \mathrm{OH}_{(\mathrm{aq})}^{-}+\mathrm{Cl}_{(\mathrm{g})}+\mathrm{NOCl}_{(\mathrm{g})}
$$

Larutan kemudian didinginkan dan disaring untuk memisahkan filtrat dengan residu dan dilakukan pengujian kadar logam $\mathrm{Hg}$ pada panjang gelombang 253,7 nm dengan menggunakan SSA-Uap dingin untuk mengetahui kandungan logam $\mathrm{Hg}$ dalam sampel tailing.

\section{Kandungan Merkuri $(\mathrm{Hg})$ dalam Sampel Tailing}

Hasil pengukuran konsentrasi merkuri dalam sampel tailing pada titik sampling I dan II dapat dilihat pada Tabel 2.

Tabel 2. Konsentrasi Merkuri dalam Sampel Tailing

\begin{tabular}{cccccc}
\hline $\begin{array}{c}\text { Titik } \\
\text { Sampling }\end{array}$ & $\begin{array}{c}\text { Kode } \\
\text { Sampel }\end{array}$ & $\begin{array}{c}\text { Konsentrasi Baca } \\
(\mu \mathrm{g} / \mathrm{L})\end{array}$ & $\begin{array}{c}\text { Konsentrasi } \\
(\mathrm{ppm})\end{array}$ & $\begin{array}{c}\mathrm{Hg} \\
\text { Rata-rata }(\mathrm{ppm})\end{array}$ & $\begin{array}{c}\mathrm{Hg} \\
\text { Rata-rata }(\mathrm{ppb})\end{array}$ \\
\hline \multirow{2}{*}{ Titik I } & S1 & 97,510 & & & \\
& S2 & 75,574 & 607,47 & 721,43 & 721430 \\
& & & 635,39 & & \\
Titik II & S1 & 65,065 & 365,45 & & 344890 \\
& S2 & 43,543 & 324,32 & 344.88 & \\
\hline
\end{tabular}

Berdasarkan Tabel 2, dapat dilihat bahwa konsentrasi merkuri pada tailing di 2 titik sampling memiliki konsentrasi yang berbeda-beda. Dari kedua tempat pengambilan sampel diperoleh kandungan merkuri tertinggi adalah pada sampel tailing di titik I yaitu dengan rata-rata sebesar $721,43 \mathrm{ppm}$ berat kering dan yang terendah adalah pada sampel tailing di titik II, yaitu sebesar 344.88 ppm berat kering. Hasil penelitian ini menunjukkan bahwa jarak dari lokasi pertambangan menentukan tingkat konsentrasi merkuri yang terakumulasi pada tailing, di mana semakin dekat jarak dari lokasi penambangan maka semakin tinggi pula konsentrasi merkuri dibandingkan dengan lokasi yang berada jauh dari lokasi pertambangan. Dari data tersebut dapat diduga bahwa penambangan emas rakyat yang menggunakan teknik amalgamasi dalam pengolahannya telah menyebabkan pencemaran sungai disekitarnya.

Tingginya konsentrasi rata-rata merkuri pada 2 lokasi pengambilan sampel menunjukkan tercemarnya lingkungan oleh merkuri. Meskipun standar baku mutu untuk tailing belum ditentukan, namun di Desa Wapsalit, konsentrasi merkuri telah melebihi 2 ppm. Menurut Veiga dan Meech (1995), tailing yang memiliki konsentrasi merkuri di atas 2 ppm berarti sudah terkontaminasi dengan merkuri yang berasal dari kegiatan pertambangan yang ada disekitar titik pengambilan sampel. Diperkirakan merkuri yang ada merupakan imbasan dari tromol yang digunakan pada proses pengolahan emas yang menggunakan merkuri. Pengolahan emas dengan teknik amalgamasi telah menyebabkan kontaminasi lingkungan.

Pencemaran merkuri banyak sekali ditemukan pada penambang emas tradisional. Penambangan emas tanpa ijin (PETI) ditemukan di berbagai tempat di Indonesia. Salah satunya terdapat di Desa Wapsalit. Di daerah Wapsalit terdapat aktivitas penambangan emas yang dilakukan di sekitar sungai Gunung Nona. Metode pengolahan yang digunakan di Gunung Nona dengan kebanyakan metode pengolahan emas tradisional yang digunakan, yaitu dengan menggunakan metode amalgamasi. Aktivitas penambangan emas rakyat di Gunung Nona Desa Wapsalit Kabupaten Buru telah berlangsung sejak tahun 2013 sampai sekarang. Pembuangan tailing langsung ke atas tanah tanpa perlakuan menyebabkan tanah tercemar merkuri sehingga kemungkinan terjadi akumulasi merkuri pada tanaman pangan yang berada di sekitarnya. Selain itu dapat pula menyebabkan infiltrasi $\mathrm{Hg}$ ke air tanah yang digunakan oleh penduduk sebagai sumber air bersih 
Limbah hasil proses amalgamasi yang telah terkontaminasi oleh merkuri berpotensi menimbulkan dampak lingkungan yangnegatif dan berbahaya bagi masyarakat yang tinggaldi sekitar Desa Wapsalit dan desa Grandeng yang berdekatan dengan lokasi pertambangan. Hal ini tentu saja sangat bebahaya karena sungai Waipamali yang menjadi pusat amalgamasi oleh para penambang emas tradisional di gunung Nona dimanfaatkan sebagai saluran irigasi untuk pengolahan sawah oleh para petani di desa Granseng sehingga sangat berpotensi mencemari lahan persawahan dari masyarakat. Hasi penelitian Wiwin dkk (2020) menunjukkan bahwa konsentrasi merkuri pada sampel tanah pada areal persawahan desa Grandeng sebesar 77,897 $\mathrm{mg} / \mathrm{kg}$ sementara pada akar tanaman padi sebesar $10,813 \mathrm{mg} / \mathrm{kg}$.

Pada ekosistem perairan unsur merkuri mengalami penurunan konsentrasi yang sangat lambat. Hal ini disebabkan oleh lemahnya merkuri yang larut dalam air, terlebih lagi akumulasinya di bagian dasar sungai seringkali dihubungkan dengan karakteristik hidrologis sungai tersebut. Jika telah menutupi seluruh limbah padat (tailing), unsur merkuri akan bertahan dalam waktu yang lama (Putra, 2011).

\section{KESIMPULAN}

Berdasarkan hasil penelitian dapat disimpulkan bahwa hasil pengukuran kandungan merkuri $(\mathrm{Hg})$ pada sampel tailing pada titik lokasi I sebesar 721,43 ppm dan titik lokasi II yaitu sebesar $344.88 \mathrm{ppm}$. Tingginya kandungan $\mathrm{Hg}$ pada sampel tailing dapat membahayakan ekosistem perairan dan kesehatan masyarakat disekitar daerah penambangan emas di Gunung Botak, Desa Wapsalit sehingga dibutuhkan penanganan lebih lanjut untuk mengurangi kandungan merkuri khususnya pada tailing hasil pengolahan emas.

\section{DAFTAR PUSTAKA}

Anderson, R. (1991). Sample Pretreatment and Separation. New York: John Willey \& Sons. Hatugalung, H. P. (2004). Logam Berat dalam Lingkungan Laut. Osean Jurnal.vol. IX. No.4 11-20. Kitong M T, Abidjulu J, \& Koleangan H S J. (2012). Analisis Merkuri (Hg) dan Arsen (As) di Sedimen Sungai Ranoyapo Kecamatan Amurang Sulawesi Utara. Jurnal MIPA Unsrat Online 1(1): 16-19.

Male, Y. T, Reichelt-Brushett AJ, Pocock M \& Nanlohy A. (2013). Recent Mercury Contamination From Artisanal Gold Mining on Buru Island, Indonesia - Potencial Future Risks to Environmental Health and Food Safety. Marine Pollution Bulletin. Vol. 77: 428-433.ir Laut (BMAL) Indonesia, Jurnal Ekoton, 2 (1) : 61-68.

Male, Y.T, Nanlohy, Ch. A, Asriningsih. (2014). Introduction Analysis of Several Levels of The Mercury $(\mathrm{Hg})$ in Shells. Ind. J. Chem. Res., 2, 136-141.

Mariwy, A., Male, Y.T., \& Manuhutu, J.B. 2019. Mercury (Hg) Contents Analysis in Sediments at Some River Estuaries in Kayeli Bay Buru Island, IOP Conf. Series: Materials Science and Engineering, Volume 546 (2): 1-7.

Mirdat, Yosep S Patádungan, Isrun (2013). Status Logam Berat Merkuri (Hg) Dalam Tanah Pada Kawasan Pengolahan Tambang Emas Di Kelurahan Poboya, Kota Palue-J. Agrotekbis 1 (2) : 127-134.

Putra, M. R. Y. K. (2011). Potensi Kontaminasi Merkuri di Lingkungan Perairan dan Manusia di Sungai Talawaan. Tesis, Universitas Sam Ratulangi.

Veiga, M. M. and Meech. (1995) . J. A... HfEx-A Heuristic on Mercury pollution in the Amazone. Water, Air and Soil Pollution

Widowati, Wahyu. (2008). Efek Toksik Logam. CV. Andi Offset : Yogyakarta.

W. P. Suci, A. Mariwiy , J. B. Manuhuttu (2020), Analisis Kadar Merkuri (Hg) Pada Tanaman Padi (oryza sativa I.) di Area Persawahan Desa Grandeng Kecamatan Lolong Guba Pulau Buru, MJoCE/Vol 10 No 1/Januari 2020/Hal. 8-15. 